ISSN: $1130-3743$

\title{
INDICADORES DEL USO DE COMPETENCIAS INFORMÁTICAS ENTRE ESTUDIANTES UNIVERSITARIOS. IMPLICACIONES FORMATIVAS Y SOCIALES
}

\author{
Indicators of computer skill use among university students. \\ Educational and social implications
}

\author{
Indicateurs d'utilisation des compétences informatiques \\ chez les étudiants universitaires. Implications formatives \\ et sociales
}

\begin{abstract}
M. ${ }^{a}$ Luisa Sevillano GarcíA* y M. ${ }^{a}$ del Pilar Quicios GarcíA*** Universidad Nacional de Educación a Distancia (UNED). Facultad de Educación. Departamento de Didáctica General, Didácticas Especiales y Organización Escolar. Departamento de Teoría de la Educación y Pedagogía. Calle Juan del Rosal, $n{ }^{\circ} 14$ (28040 Madrid). Correo-e: *mlsevillano@edu.uned.es; **"pquicios@edu.uned.es
\end{abstract}

Fecha de recepción: enero de 2012

Fecha de aceptación definitiva: abril de 2012

Biblid [(1130-3743) 24, 1-2012, 151-182]

\section{RESUMEN}

El presente artículo pretende difundir resultados encontrados en el estudio preliminar del Proyecto de Investigación SEJ 2004-06803 I+D. Se señalan indicadores de uso de competencias informáticas desarrolladas por dos grupos de universitarios españoles y necesidades formativas declaradas para conseguir autonomía en el uso de las competencias informáticas. Las muestras analizadas estuvieron compuestas por dos grupos de estudiantes de primero de Comunicación Audiovisual y tercero de Periodismo de la Universidad Complutense de Madrid. Cada grupo lo conformaron 60 estudiantes que respondieron un cuestionario de naturaleza cuantitativa (escala 
Likert) y una serie de cuestiones de respuesta cualitativa. Entre las conclusiones encontradas se señala que la edad no es factor determinante para el uso de competencias informáticas. Tampoco lo es la titulación estudiada. Como necesidades formativas declaradas se encuentran una instrucción sistemática en herramientas de uso y una formación educativa que ponga límites al uso relacional de herramientas virtuales.

Palabras clave: competencias, indicadores de uso de competencias, nativos digitales, inmigrantes digitales, usuarios informáticos correctamente alfabetizados.

\section{SUMMARY}

This article divulges the findings of the preliminary study for Research Project SEJ 2004-06803 I+D. It provides indicators of the use of the computer skills developed by two groups of Spanish university students. It then indicates the training the sample groups under study declared necessary in order to gain autonomy in their use of computer skills. The sample groups analyzed were two groups of students enrolled in the first year of the audiovisual communication curriculum and the third year of the journalism curriculum at the Complutensian University of Madrid. Each group was made up of 60 students who answered a quantitative questionnaire (Likert scale) and a series of questions requiring qualitative answers. One finding was that age is not a telling factor in the use of computer skills, nor is the curriculum a student has chosen to follow. The declared educational needs include systematic instruction in tools and educational training that places limits on the relational use of virtual tools.

Key words: skills, skill use indicators, digital natives, digital immigrants, welleducated computer users.

\section{SOMMAIRE}

Le présent article cherche à diffuser les résultats obtenus dans l'étude préliminaire du Projet de recherche SEJ 2004-06803 R+D. Nous y signalons les indicateurs d'utilisation des compétences informatiques développées chez deux groupes d'universitaires espagnols. De plus, nous indiquons les besoins déclarés en formation, à l'intérieur des échantillons étudiés, en vue d'atteindre une autonomie dans l'utilisation des compétences informatiques. Les échantillons analysés étaient composés de deux groupes d'étudiants: un groupe de première année en communication audiovisuelle et un groupe de troisième année en journalisme de l'Université Complutense de Madrid. Chaque groupe était composé de 60 étudiants qui ont répondu à un questionnaire de nature quantitative (échelle Likert) et à des questions de nature qualitative. Parmi les conclusions qui ont été tirées, nous signalons que l'âge n'est pas un facteur déterminant dans l'utilisation des compétences informatiques. Pas plus que ne l'est le programme d'étude. Parmi les besoins déclarés en formation, il y a l'instruction systématique d'outils d'utilisation et une formation en classe qui mette des limites à l'utilisation relationnelle d'outils virtuels.

Mots clés: compétences, indicateurs d'utilisation des compétences, natifs du numérique, immigrants du numérique, utilisateurs informatiques correctement alphabétisés. 


\section{INTRODUCCIÓN}

Hasta hace una década, padres y profesores de niveles de enseñanzas no universitarias -supuestos inmigrantes digitales o, en el mejor de los casos, colonos digitales- ansiaban que las nuevas generaciones, es decir, sus hijos y alumnos, dominaran en el menor tiempo posible el máximo número de programas informáticos. Para conseguir este objetivo, tanto a nivel estatal como autonómico y comarcal se arbitraron múltiples campañas de alfabetización digital. Éstas conllevaron importantes subvenciones y financiaciones destinadas a la adquisición de hardware y el aprendizaje de software básico. La apuesta dio sus frutos y, hoy por hoy, la alfabetización digital es un hecho entre las nuevas generaciones por lo que carece de sentido seguir insistiendo en ella.

La sociedad y la universidad tienen otras preocupaciones. Académicamente se desea conocer el empleo que hacen las poblaciones alfabetizadas digitalmente de las tecnologías y de las herramientas informáticas. Su uso interesa en dos sentidos: como espacios de información y, sobre todo, como generadores de espacios de acción o lugares de relación (García del Dujo, 2009). Esta preocupación y otras similares son, actualmente, campo de investigación y estudio de varios académicos. Bernal (2009, 96), en un estudio titulado "Cibermundo y educación. Bosquejo de un nuevo marco formativo en contextos postmodernos", afirma que: "el ciberespacio, la ciencia y la técnica ha de aceptarse como mecanismo de organización social en un mundo cada vez más tecnificado. No se trata de hacer apología de la ciencia y la técnica, sino de promulgar su proceso de admisión crítica, puesto que se corre el riesgo de no socializarla con la suficiente premura".

García del Dujo (2009, 126), entre otros, en el estudio titulado "Análisis del espacio de los entornos virtuales de formación" afirma que: "procede superar ya la fase administrativa, política, ingenieril... para adentrarnos en los usos, prácticas y percepciones, representaciones y manifestaciones que los usuarios tienen y hacen de estas tecnologías en sus mundos". Sevillano ([dir.] 2009, 282) en otro estudio concluye igualmente que: "La edad juega un papel importante en el conocimiento y manejo de las herramientas virtuales. Son los más jóvenes, los más intuitivos y, por tanto, aventajados usuarios tecnológicos de instrucciones básicas”. Atendiendo a su edad cronológica y al diseño curricular que han seguido en su formación académica, en rigor, una gran parte de los estudiantes universitarios españoles podrían ser considerados nativos digitales si se asume la idea de Palfrey y Gasser (2008). Estos autores definen como nativos digitales a todos los nacidos después de 1980, cuando la utilización de redes sociales en Internet empezaba a despuntar. Prensky (2001) insiste en la misma idea. Este autor entiende que los nativos digitales han nacido en un periodo en el que el uso de Internet estaba ya totalmente generalizado. Considera que este tipo de usuarios entienden la Red como un elemento vertebrador de su mundo relacional. Aprenden en red, de la Red y desde la Red. Conciben el ciberespacio como un espacio lúdico y la producción digital como un divertido juego. Sin embargo, García y Melaré $(2009,72)$ dudan de que 
la edad cronológica del usuario sea una razón suficiente para generar la rígida y artificial clasificación de inmigrante y nativo digital. Las autoras afirman: «[...] el contexto (cultura, sociedad, ambiente, educación, etc.) en el que se mueven (los usuarios de herramientas informáticas) es lo que condiciona a los sujetos para ser nativos o inmigrantes digitales".

Los inmigrantes digitales (padres y profesores), por el contrario, son individuos que se han formado personal, social y profesionalmente en un mundo analógico. En su volitiva, necesaria u obligada convivencia con el mundo digital han aprendido el manejo del ordenador estudiando manuales de usuario de distintos softwares, siguiendo costosos cursos específicos o recordando concretos comandos necesarios para la realización de cada una de las tareas abordadas.

Los inmigrantes digitales se están adaptando, más lentamente, a la realidad virtual, pero lo están haciendo. En su evolución instructiva hacia la colonización virtual consideran el PC -en su terminología, el ordenador- un instrumento e Internet, la red de redes. Usan la tecnología con respeto, desconfianza y/o temor. El aprendizaje de nuevas utilidades les supone superar retos y les exige esfuerzo. La tecnología es vista como un servicio que cuando se domina facilita el trabajo. No tiene otra utilidad natural.

Sevillano y Quicios como conclusiones del Proyecto de Investigación SEJ 200406803 I+D han encontrado un nuevo grupo de infociudadanos que rompen los rígidos y excluyentes esquemas de inmigrante o nativo digital. A este nuevo subgrupo de consumidores de tecnología informática se les ha denominado usuarios informáticos correctamente alfabetizados. Este colectivo estaría compuesto por los niños nacidos en los últimos años de la década de los ochenta y los primeros de la década de los noventa. Son poblaciones sobre las que incidió, aunque de manera desigual, la inversión social en alfabetización informática desplegada en este país. Aquellos niños, en estos momentos, ocupan las aulas universitarias y son objeto del nuevo proyecto de investigación "Aprendizaje ubicuo con dispositivos móviles: desarrollo de un mapa de competencias en educación superior" (EDU2010-17420) dirigido también por la Dra. Sevillano García.

El presente artículo trata de difundir los resultados encontrados en el estudio preliminar del Proyecto de Investigación SEJ 2004-06803 I+D. Este estudio preliminar se centró en señalar los indicadores de uso de competencias informáticas desarrolladas por los actuales universitarios españoles (nativos digitales y usuarios informáticos correctamente alfabetizados). Concibió las competencias informáticas como el conjunto de conocimientos, usos y conductas que permiten al usuario conseguir los objetivos de uso que se ha propuesto. Justamente, por el contenido de esta concepción de competencia informática, interesó también conocer las necesidades formativas declaradas por las muestras estudiadas.

Los estudiantes que tomaron parte en el estudio, además de indicar el uso que hacían de las competencias informáticas, señalaron las carencias formativas que les impiden desenvolverse, autónomamente, con TIC. En este artículo, quieren verterse resultados válidos encontrados tras la aplicación de un cuestionario diseñado para 
medir la frecuencia de uso de distintos indicadores de competencias informáticas. Se trata de visualizar indicadores de uso de las mismas y señalar las carencias formativas declaradas por los propios sujetos implicados en el estudio.

\section{COMPETENCIAS VERSUS INDICADORES DE USO DE COMPETENCIAS}

El concepto competencia empieza a ser una expresión propia del lenguaje ordinario lo que conlleva, indudablemente, la pérdida de su génesis conceptual originaria. El nacimiento de este neologismo amplió el lenguaje empresarial y, paralelamente, cambió el criterio para medir los éxitos profesionales. Por primera vez en la historia empresarial se señaló la importancia que tenía el verificar competencias, en lugar de inteligencia, para lograr mayor competitividad laboral. Desde ese momento se utilizan, habitualmente, los modelos de competencias para establecer los elementos fundamentales de la tarea organizativa y productiva.

En el mundo académico es Bloom (1968) quien introduce este término al publicar "Aprendizaje para el Dominio". En este artículo señala que entre el 90 y el 95\% de los alumnos pueden aprender lo que se les enseñe si cuentan con las condiciones adecuadas para ello. Éste y otros trabajos similares fueron el germen del movimiento Enseñanza basada en competencias, tipo de enseñanza fundamentada en cinco principios: Todo aprendizaje es individual. El individuo se orienta por las metas a lograr. El proceso de aprendizaje es más fácil cuando el individuo sabe qué es exactamente lo que se espera de él. El conocimiento preciso de los resultados también facilita el aprendizaje. Es más probable que un alumno haga lo que se espera de él y lo que él mismo desea, si toma con responsabilidad las tareas de aprendizaje

Avanzando más en la realidad competencial, en el Proyecto 128 (Cinterfor) OIT) (Lizano y Trejos, 1975) se define la competencia como la capacidad real para alcanzar un objetivo o resultado en un contexto dado. A partir de estos trabajos la idea de competencia comenzó a consolidarse y popularizarse aunque, ciertamente, su idea existiese desde que, en 1949, Parsons elaborara un esquema conceptual para estructurar situaciones sociales según una serie de variables dicotómicas. Una de esas variables dicotómicas fue el concepto de Acheviement (valorar a una persona por la obtención de unos resultados concretos en lugar de hacerlo por las cualidades, más o menos, arbitrariamente atribuidas) vs Ascription.

En el mundo académico, el término y concepto de competencia viene fraguándose, al menos, desde hace medio siglo. En un primer momento vinculado a modelos conductistas. En estos momentos, la globalización comercial, los avances científicos y tecnológicos, los nuevos esquemas en la organización del trabajo, la diversidad y movilidad de los mercados laborales, la apuesta por la individualización de los aprendizajes, el traspaso de responsabilidades a los aprendices, la vinculación de las enseñanzas al ejercicio profesional, la influencia empresarial en la reorganización de los estudios y aspectos similares inciden tanto en los planteamientos del término como en el concepto de competencia. Aun así este término se 
INDICADORES DEL USO DE COMPETENCIAS INFORMÁTICAS ENTRE ESTUDIANTES UNIVERSITARIOS

ha ido resistiendo a incardinarse en el mundo educativo. Ha habido que esperar a que el Espacio Europeo de Educación Superior (EEES), en pleno siglo XXI, forzara tanto a la Comunidad científica como al contexto educativo a asumir el término competencia. Ésta lo ha aceptado pero sin redefinirlo ni matizarlo.

Leví (2011) tras haber analizado, en su tesis doctoral, numerosas definiciones de competencia considera que, tal vez, haya llegado el momento -en el mundo académico- de reconceptualizar este vocablo. La razón es clara: en educación, el significado primigenio de la palabra competencia puede no abarcar todos los aspectos que debería contener. Leví (2011, 152) considera que:

La formulación correcta de una competencia debe expresar la consecución de un conocimiento, capacidad, actitud o combinación en mayor o menor grado de estas componentes de manera clara, mediante la utilización de los términos precisos que permitan delimitar su contenido e identificar la forma de lograrlo. Se trata de formulaciones desiderativas como la expresión de unos logros indicados por los sintagmas que conforman el objeto del deseo.

En los años 80, y derivadas de la bibliografía norteamericana de la década anterior, surgieron en Europa publicaciones sobre evaluación basada en competencias. A raíz de estos avances, en casi todos los países desarrollados primero, y luego en países en vías de desarrollo, fueron imponiéndose Sistemas Nacionales de Cualificación y Formación Laboral fundamentados en el modelo de Competencias.

Actualmente, la competencia ya se relaciona con un nuevo paradigma de producción superando el modelo de calificaciones. Ahora se capacita para situaciones polivalentes. Las competencias se han usado en educación y en el ámbito laboral desde los años setenta con un enfoque propiamente conductista. En los años ochenta, el enfoque se tornó más holístico en el Reino Unido, Estados Unidos, Australia, Canadá, Francia, Alemania, Nueva Zelanda, España, México, Argentina, Bolivia, Brasil, Chile, Colombia y Costa Rica, entre otros países.

Todos los movimientos y avances reseñados llevaron a los gobiernos y a los sectores empresariales a aunar esfuerzos y crear programas junto al sector educativo para responder al reto que suponía la sociedad del conocimiento. A pesar de todo lo señalado, hasta el momento, no existe unanimidad de criterio a la hora de definir qué se entiende por competencia. Irigoin y Vargas (2002) ya señalaron que en el término competencia se encierran diferentes conceptos como: aptitudes y actitudes, capacidad de enfrentarse con nuevos contextos y responder a nuevos retos. Poblete (2004) consideró que las competencias constan de los siguientes componentes: SABER: Datos, hechos, informaciones, conceptos, conocimientos. SABER HACER: Habilidades, destrezas, técnicas para aplicar y transferir el saber a la actuación. SABER SER: Normas, actitudes, intereses, valores que llevan a tener unas convicciones y asumir unas responsabilidades. SABER ESTAR: Predisposición al entendimiento y a la comunicación interpersonal, favoreciendo un comportamiento colaborativo. Rodríguez (2006) por su lado recopiló 
elementos comunes en las diferentes definiciones de competencia. De entre ellos, se señalan los siguientes: Son características permanentes de la persona. Se ponen de manifiesto cuando se ejecuta exitosamente una tarea, laboral o de otra índole. Tienen una relación causal con el rendimiento laboral. Pueden ser generalizables a más de una actividad. Por competencia se entiende esa combinación de actitudes, aptitudes, atributos y comportamientos vinculados a un ejercicio profesional exitoso que busca transformar el conocimiento en acción. Guardan relación con la realización de alguna actividad, transferencia de conocimientos a nuevas situaciones, organización del trabajo, innovación y resultado de combinar varios recursos. Busca el desarrollo social, cognitivo, procesos de socialización y uso de recursos.

\section{Diseño MetodolóGico}

\subsection{Objetivos}

- Conocer el grado de competencia digital para el uso de herramientas de comunicación virtual alcanzado entre los actuales universitarios españoles.

- Descubrir si el usuario universitario ha alcanzado un equilibrio entre el saber (instrucción), saber hacer (capacitación), saber ser (formación) y saber estar (comportamiento).

- Identificar los indicadores de uso de competencias informáticas de dos grupos de estudiantes universitarios españoles matriculados en primer curso de Comunicación Audiovisual y tercer curso de Periodismo, respectivamente.

- Determinar necesidades formativas que los estudiantes que han tomado parte en el estudio manifiestan tener a la hora de enfrentarse, autónomamente, a la utilización de distintas herramientas informáticas.

\subsection{Metodología. Muestra e instrumentos}

Para obtener los datos se seleccionaron, inicialmente, dos grupos de ciento veinte estudiantes universitarios de Ciencias de la Información. El primer grupo estaba formado por sesenta universitarios que estudiaban primer curso de Comunicación Audiovisual en la Universidad Complutense de Madrid. El segundo grupo estudiaba tercer curso de Periodismo en la misma Universidad. La muestra presentaba características tanto comunes como diferenciales. Las características distintivas no anulaban la validez del estudio pues sólo hacían referencia a la edad cronológica de la muestra, variando ésta en \pm 2 años, y a la titulación estudiada (dos variantes de un mismo campo de conocimiento). 
M. ${ }^{a}$ LUISA SEVILLANO GARCÍA Y M. ${ }^{a}$ DEL PILAR QUICIOS GARCÍA

INDICADORES DEL USO DE COMPETENCIAS INFORMÁTICAS ENTRE ESTUDIANTES UNIVERSITARIOS

CuAdro 1. CARACTERÍsticas De la Muestra

\begin{tabular}{|c|c|c|}
\hline CARACTERÍSTICAS DE LA MUESTRA & PUNTOS COMUNES & PUNTOS DIFERENCIALES \\
\hline Característica analizada & Estudiantes universitarios & Edades entre 19 y 22 años \\
\hline Estudios realizados & $\begin{array}{c}\text { Idéntico campo de } \\
\text { conocimiento }\end{array}$ & $\begin{array}{c}\text { Estudios de Periodismo } \\
\text { Estudios de Comunicación } \\
\text { Audiovisual }\end{array}$ \\
\hline Universidad & Complutense de Madrid & \\
\hline Lugar de residencia & Madrid & \\
\hline Situación laboral & Inactivos & \\
\hline
\end{tabular}

A la muestra así constituida se le aplicó un cuestionario adaptado partiendo del diseñado por Aliaga, Orellana y Suárez (2004). Consta de treinta y dos ítems, veintiséis de ellos se respondían a través de una escala tipo Likert y el resto del cuestionario con apreciaciones personales explicativas o respuestas abiertas. La situación en la que se aplicó el cuestionario fue idéntica para los dos grupos estudiados, ofreciendo tiempo suficiente para pensar, reflexionar y contestar. Para facilitar la respuesta se acomodaron los enunciados de los indicadores de uso de competencia informática a la forma de expresión habitual de la población juvenil.

4. RESULTADOS DE LOS DATOS OBTENIDOS EN EL ESTUDIO EXPLORATORIO DEL PROYECTO SEJ 2004-06803 I+D

Para determinar los estadísticos que se iban a aplicar a cada una de las muestras estudiadas se calculó su normalidad a través del test de normalidad Kolmogorov-Smirnov verificándose que la muestra no cumple el criterio de normalidad. Las mediciones revelaron que no se satisfacen los requisitos para utilizar una media aritmética como unidad de medida. Por este motivo se inició el estudio estadístico realizando un estudio de frecuencias de las dos muestras de estudiantes. En cuadros adjuntos se van a indicar las comparativas de frecuencias de uso de indicadores de competencia entre los estudiantes de primer curso de Comunicación Audiovisual y los de tercero de Periodismo. Con esta comparativa quiere visualizarse las competencias que sería necesario desarrollar en cada una de las actividades o herramientas medidas.

Este indicador de uso de competencia resulta fundamental para medir la capacitación inicial en el conocimiento de medios informáticos entre los estudiantes que inician la titulación de Comunicación Audiovisual. Los resultados obtenidos en esta exploración llaman la atención puesto que cuarenta y cuatro estudiantes de Comunicación Audiovisual declaran usarlo solamente (nada+algo). En el extremo contrario, cuatro responden usarlo (mucho+muchísimo) frente a cuarenta y un estudiantes de Periodismo que responden (nada+algo) y once que lo hacen en la escala (mucho+muchísimo). Sumando las frecuencias de uso catalogadas como 
bastante, mucho y muchísimo de ambos grupos - por separado- puede concluirse que ambos grupos usan este indicador de competencia de manera deficiente con valores porcentuales del 26,7\% y el 31,6\% respectivamente. Es más llamativo el resultado obtenido al comprobarse que los estudiantes de Periodismo superan en indicador de uso a los estudiantes de Comunicación Audiovisual (titulación más cercana a esta utilidad que Periodismo).

\section{TABLA 1. CONFIGURAR Y MANTENER REDES}

\begin{tabular}{|c|c|c|c|c|c|}
\hline Titulación. Curso & \multicolumn{5}{|c|}{ Valoración. Cuestionarios válidos } \\
\hline \multirow{7}{*}{$\begin{array}{c}\text { Comunicación } \\
\text { Audiovisual. } \\
\text { 1. }{ }^{\text {er }} \text { Curso }\end{array}$} & Valores & Frecuencia & Porcentaje & $\begin{array}{c}\text { Porcentaje } \\
\text { válido }\end{array}$ & $\begin{array}{l}\text { Porcentaje } \\
\text { acumulado }\end{array}$ \\
\hline & Nada & 31 & 51,7 & 51,7 & 51,7 \\
\hline & Algo & 13 & 21,7 & 21,7 & 73,3 \\
\hline & Bastante & 12 & 20,0 & 20,0 & 93,3 \\
\hline & Mucho & 1 & 1,7 & 1,7 & 95,0 \\
\hline & Muchísimo & 3 & 5,0 & 5,0 & 100,0 \\
\hline & Total & 60 & 100,0 & 100,0 & \\
\hline \multirow{6}{*}{$\begin{array}{c}\text { Periodismo. } \\
3 \text {. }^{\text {er }} \text { Curso }\end{array}$} & Nada & 32 & 53,3 & 53,3 & 53,3 \\
\hline & Algo & 9 & 15,0 & 15,0 & 68,3 \\
\hline & Bastante & 8 & 13,3 & 13,3 & 81,7 \\
\hline & Mucho & 2 & 3,3 & 3,3 & 85,0 \\
\hline & Muchísimo & 9 & 15,0 & 15,0 & 100,0 \\
\hline & Total & 60 & 100,0 & 100,0 & \\
\hline
\end{tabular}

La herramienta básica para comunicarse tanto en Comunicación Audiovisual como en Periodismo es la palabra. Ésta cuando quiere perpetuarse en el tiempo tiene que transmitirse de manera escrita a través de cualquier documento de texto. Aun partiendo de esta certeza inicial, un estudiante de Comunicación Audiovisual ha accedido a la titulación con un uso de este indicador de competencia bajísimo (contesta en la categoría algo). Lo que es más preocupante es que siete estudiantes de tercer curso de Periodismo respondan en la horquilla (nada+algo). En el extremo contrario (mucho+muchísimo) es la respuesta mayoritaria (cincuenta estudiantes) en ambas titulaciones. Sumando las frecuencias de uso catalogadas como bastante, mucho y muchísimo de ambos grupos - por separado- puede concluirse que ambos grupos usan este indicador de competencia de manera sobresaliente con valores porcentuales del $98,4 \%$ y el $88,3 \%$, por lo que ninguno de los grupos precisa formación sobre este indicador de uso de competencia. 
TABLA 2. CREAR Y EDITAR DOCUMENTOS DE TEXTO

\begin{tabular}{|c|c|c|c|c|c|}
\hline \multirow{2}{*}{ Titulación. Curso } & \multicolumn{5}{|c|}{ INDICADOR: Creo y edito documentos de texto } \\
\hline \multirow{4}{*}{$\begin{array}{c}\text { Comunicación } \\
\text { Audiovisual. } \\
\text { 1. }{ }^{\text {Cr Curso }} \\
\end{array}$} & Valores & Frecuencia & Porcentaje & $\begin{array}{c}\text { Porcentaje } \\
\text { válido }\end{array}$ & $\begin{array}{c}\text { Porcentaje } \\
\text { acumulado }\end{array}$ \\
\cline { 2 - 6 } & Nada & - & - & - & - \\
\cline { 2 - 6 } & Algo & 1 & 1,7 & 1,7 & 1,7 \\
\cline { 2 - 6 } & Bastante & 9 & 15,0 & 15,0 & 16,7 \\
\cline { 2 - 6 } & Mucho & 10 & 16,7 & 16,7 & 33,3 \\
\cline { 2 - 6 } & Muchísimo & 40 & 66,7 & 66,7 & 100,0 \\
\cline { 2 - 6 } & Total & 60 & 100,0 & 100,0 & \\
\hline \multirow{4}{*}{$\begin{array}{c}\text { Periodismo. } \\
\text { er Curso }\end{array}$} & Nada & 2 & 3,3 & 3,3 & 3,3 \\
\cline { 2 - 6 } & Algo & 5 & 8,3 & 8,3 & 11,7 \\
\cline { 2 - 6 } & Bastante & 3 & 5,0 & 5,0 & 16,7 \\
\cline { 2 - 6 } & Mucho & 17 & 28,3 & 28,3 & 45,0 \\
\cline { 2 - 6 } & Muchísimo & 33 & 55,0 & 55,0 & 100,0 \\
\cline { 2 - 6 } & Total & 60 & 100,0 & 100,0 & \\
\hline
\end{tabular}

TABLA 3. EDITAR TABLAS

\begin{tabular}{|c|c|c|c|c|c|}
\hline \multicolumn{5}{|c|}{ INDICADOR: Edito tablas } \\
\hline Titulación. Curso & \multicolumn{5}{|c|}{ Valoración. Cuestionarios válidos } \\
\hline \multirow{4}{*}{$\begin{array}{c}\text { Comunicación } \\
\text { Audiovisual. } \\
\text { 1. }{ }^{\text {er }} \text { Curso } \\
\end{array}$} & Valores & Frecuencia & Porcentaje & $\begin{array}{c}\text { Porcentaje } \\
\text { válido }\end{array}$ & $\begin{array}{c}\text { Porcentaje } \\
\text { acumulado }\end{array}$ \\
\cline { 2 - 6 } & Nada & 3 & 5,0 & 5,0 & 5,0 \\
\cline { 2 - 6 } & Algo & 12 & 20,0 & 20,0 & 25,0 \\
\cline { 2 - 6 } & Bastante & 6 & 10,0 & 10,0 & 35,0 \\
\cline { 2 - 6 } & Mucho & 20 & 33,3 & 33,3 & 68,3 \\
\cline { 2 - 6 } & Muchísimo & 19 & 31,7 & 31,7 & 100,0 \\
\cline { 2 - 6 } & Total & 60 & 100,0 & 100,0 & \\
\hline \multirow{4}{*}{$\begin{array}{c}\text { Periodismo. } \\
\text { er Curso }\end{array}$} & Nada & - & - & - & - \\
\cline { 2 - 6 } & Algo & 14 & 23,3 & 23,3 & 23,3 \\
\cline { 2 - 6 } & Bastante & 16 & 26,7 & 26,7 & 50,0 \\
\cline { 2 - 6 } & Mucho & 16 & 26,7 & 26,7 & 76,7 \\
\cline { 2 - 6 } & Muchísimo & 14 & 23,3 & 23,3 & 100,0 \\
\cline { 2 - 6 } & Total & 60 & 100,0 & 100,0 & \\
\hline
\end{tabular}


Los estudiantes usan este indicador de forma desigual (Tabla 3). Quince estudiantes de Comunicación Audiovisual declaran usarlo solamente (nada+algo). En el extremo contrario, treinta y nueve, responden usarlo (mucho+muchísimo) frente a catorce de Periodismo que responden (nada+algo) y treinta que responden (mucho+muchísimo). Sumando las frecuencias de uso catalogadas como bastante, mucho y muchísimo de ambos grupos - por separado- puede concluirse que ambos grupos usan este indicador de competencia de manera notable con valores porcentuales del $75 \%$ y el $76,7 \%$ respectivamente por lo que ninguno de los grupos precisa formación sobre este indicador de uso de competencia.

\section{TABLA 4. EDITAR IMÁGENES}

\begin{tabular}{|c|c|c|c|c|c|}
\hline \multicolumn{6}{|c|}{ INDICADOR: Edito imágenes } \\
\hline Titulación. Curso & & Valorac & Cuestionar & válidos & \\
\hline \multirow{7}{*}{$\begin{array}{l}\text { Comunicación } \\
\text { Audiovisual. } \\
\text { 1. }{ }^{\text {er }} \text { Curso }\end{array}$} & Valores & Frecuencia & Porcentaje & $\begin{array}{c}\text { Porcentaje } \\
\text { válido }\end{array}$ & $\begin{array}{l}\text { Porcentaje } \\
\text { acumulado }\end{array}$ \\
\hline & Nada & - & - & - & - \\
\hline & Algo & 8 & 13,3 & 13,3 & 13,3 \\
\hline & Bastante & 10 & 16,7 & 16,7 & 30,0 \\
\hline & Mucho & 17 & 28,3 & 28,3 & 58,3 \\
\hline & Muchísimo & 25 & 41,7 & 41,7 & 100,0 \\
\hline & Total & 60 & 100,0 & 100,0 & \\
\hline \multirow{6}{*}{$\begin{array}{c}\text { Periodismo. } \\
3 .^{\text {er }} \text { Curso }\end{array}$} & Nada & - & - & - & - \\
\hline & Algo & 9 & 15,0 & 15,0 & 15,0 \\
\hline & Bastante & 18 & 30,0 & 30,0 & 45,0 \\
\hline & Mucho & 14 & 23,3 & 23,3 & 68,3 \\
\hline & Muchísimo & 19 & 31,7 & 31,7 & 100,0 \\
\hline & Total & 60 & 100,0 & 100,0 & \\
\hline
\end{tabular}

Todos los estudiantes usan este indicador (Tabla 4) aunque en proporciones diferentes. Ocho estudiantes de Comunicación Audiovisual declaran usarlo solamente algo. En el extremo contrario, cuarenta y dos, responden usarlo (mucho+muchísimo) frente a nueve estudiantes de Periodismo que responden usarlo algo y treinta y tres que responden usarlo (mucho+muchísimo). Sumando las frecuencias de uso catalogadas como bastante, mucho y muchísimo de ambos grupos - por separado- puede concluirse que ambos grupos usan este indicador de competencia de manera sobresaliente con valores porcentuales del $86,7 \%$ y el $85 \%$ respectivamente por lo que ninguno de los grupos precisa formación sobre este indicador de uso de competencia. No obstante, aumentar los conocimientos entre los estudiantes de primer curso de Comunicación Audiovisual, dada la naturaleza de su titulación, redundaría en una mayor autonomía frente a medios. 
Esta habilidad (Tabla 5) supone un trabajo complejo, sin embargo, los estudiantes mayores ya disponen de unos conocimientos curriculares recibidos en la disciplina Tecnología de la Información y por tanto, por vez primera, muestran unos dominios superiores a los de sus compañeros recién ingresados en la Facultad. Este dato abre una reflexión sobre la capacidad innata o adquirida para enfrentarse a las herramientas informáticas. Tal vez se esté ante una realidad más educativa y adquirida que natural pudiendo empezar a romperse el rígido y artificial dualismo existente entre nativos e inmigrantes digitales y comenzar a popularizar el vocablo ofrecido por las autoras del artículo usuarios informáticos correctamente alfabetizados.

Si llamaban la atención las frecuencias de uso de competencias relacionadas con la creación y edición de documentos de texto, las respuestas dadas al indicador de uso de competencia que nos ocupa son más llamativas, todavía, puesto que dieciséis estudiantes de Comunicación Audiovisual han accedido a la titulación con un indicador de uso de esta competencia bajísimo (contestan en las categorías nada+algo). Frente a este dato todos los estudiantes de tercero de Periodismo utilizan este indicador (sólo ocho lo utilizan en la categoría algo). En el extremo contrario (mucho+muchísimo) es la respuesta mayoritaria con treinta y cinco y treinta y cuatro respuestas, respectivamente, en ambas titulaciones.

Sumando las frecuencias de uso catalogadas como bastante, mucho y muchísimo de ambos grupos - por separado- puede concluirse que ambos grupos usan este indicador de competencia de manera notable con valores porcentuales del $73,3 \%$ y el $86,7 \%$ por lo que ninguno de los grupos precisa formación sobre este indicador de uso de competencia.

\section{TABla 5. CONFIGURACión AVANZADA DE DOCUMENTOS TEXTUALES}

\begin{tabular}{|c|c|c|c|c|c|}
\hline \multicolumn{6}{|c|}{ INDICADOR: Realizo una configuración avanzada de documentos de texto } \\
\hline Titulación. Curso & \multicolumn{5}{|c|}{ Valoración. Cuestionarios válidos } \\
\hline \multirow{4}{*}{$\begin{array}{c}\text { Comunicación } \\
\text { Audiovisual. } \\
1 .{ }^{\text {er }} \text { Curso }\end{array}$} & Valores & Frecuencia & Porcentaje & $\begin{array}{c}\text { Porcentaje } \\
\text { válido }\end{array}$ & $\begin{array}{c}\text { Porcentaje } \\
\text { acumulado }\end{array}$ \\
\cline { 2 - 6 } & Nada & 3 & 5,0 & 5,0 & 5,0 \\
\cline { 2 - 6 } & Algo & 13 & 21,7 & 21,7 & 26,7 \\
\cline { 2 - 6 } & Bastante & 9 & 15,0 & 15,0 & 41,7 \\
\cline { 2 - 6 } & Mucho & 15 & 25,0 & 25,0 & 66,7 \\
\cline { 2 - 6 } & Muchísimo & 20 & 33,3 & 33,3 & 100,0 \\
\cline { 2 - 6 } & Total & 60 & 100,0 & 100,0 & \\
\hline \multirow{4}{*}{$\begin{array}{c}\text { Periodismo. } \\
\text { er Curso }\end{array}$} & Nada & - & - & - & - \\
\cline { 2 - 6 } & Algo & 8 & 13,3 & 13,3 & 13,3 \\
\cline { 2 - 6 } & Bastante & 18 & 30,0 & 30,0 & 43,3 \\
\cline { 2 - 6 } & Mucho & 16 & 26,7 & 26,7 & 70,0 \\
\cline { 2 - 6 } & Muchísimo & 18 & 30,0 & 30,0 & 100,0 \\
\cline { 2 - 6 } & Total & 60 & 100,0 & 100,0 & \\
\hline
\end{tabular}


M. ${ }^{a}$ LUISA SEVILLANO GARCÍA Y M. ${ }^{a}$ DEL PILAR QUiCIOS GARCíA

INDICADORES DEL USO DE COMPETENCIAS INFORMÁTICAS ENTRE ESTUDIANTES UNIVERSITARIOS

TABla 6. REALIZAR GRÁFICOS A PARTIR DE DATOS

\begin{tabular}{|c|c|c|c|c|c|}
\hline \multicolumn{5}{|c|}{ INDICADOR: Realizo gráficos a partir de datos } \\
\hline Titulación. Curso & \multicolumn{5}{|c|}{ Valoración. Cuestionarios válidos } \\
\hline \multirow{4}{*}{$\begin{array}{c}\text { Comunicación } \\
\text { Audiovisual. } \\
1 .{ }^{\text {er }} \text { Curso }\end{array}$} & Valores & Frecuencia & Porcentaje & $\begin{array}{c}\text { Porcentaje } \\
\text { válido }\end{array}$ & $\begin{array}{c}\text { Porcentaje } \\
\text { acumulado }\end{array}$ \\
\cline { 2 - 6 } & Nada & 13 & 21,7 & 21,7 & 21,7 \\
\cline { 2 - 6 } & Algo & 21 & 35,0 & 35,0 & 56,7 \\
\cline { 2 - 6 } & Bastante & 10 & 16,7 & 16,7 & 73,3 \\
\cline { 2 - 6 } & Mucho & 10 & 16,7 & 16,7 & 90,0 \\
\cline { 2 - 6 } & Muchísimo & 6 & 10,0 & 10,0 & 100,0 \\
\cline { 2 - 6 } & Total & 60 & 100,0 & 100,0 & \\
\hline \multirow{4}{*}{$\begin{array}{c}\text { Periodismo. } \\
\text { er Curso }\end{array}$} & Nada & - & - & - & - \\
\cline { 2 - 6 } & Algo & 24 & 40,0 & 40,0 & 40,0 \\
\cline { 2 - 6 } & Bastante & 12 & 20,0 & 20,0 & 60,0 \\
\cline { 2 - 6 } & Mucho & 13 & 21,7 & 21,7 & 81,7 \\
\cline { 2 - 6 } & Muchísimo & 11 & 18,3 & 18,3 & 100,0 \\
\cline { 2 - 6 } & Total & 60 & 100,0 & 100,0 & \\
\hline
\end{tabular}

Los estudiantes usan este indicador de forma desigual (Tabla 6). Treinta y cuatro estudiantes de Comunicación Audiovisual declaran usarlo solamente (nada+algo). En el extremo contrario, dieciséis, responden usarlo (mucho+muchísimo) frente a veinticuatro estudiantes de Periodismo que responden usarlo algo y treinta y cuatro que responden usarlo (mucho+muchísimo). Sumando las frecuencias de uso catalogadas como bastante, mucho y muchísimo de ambos grupos -por separado- puede concluirse que ambos grupos usan este indicador de competencia de manera desigual con valores porcentuales del 43,4\% y el 60\% respectivamente por lo que el grupo de estudiantes de primero de Comunicación Audiovisual sería conveniente que ampliara conocimientos de uso de esta competencia.

Al aplicar la prueba no paramétrica de Mann-Whitney-Wilcoxon a las dos muestras estudiadas y tomando como variable de agrupación la edad de los sujetos estudiados, como se expondrá en otra parte del artículo, se observará que existen diferencias significativas entre las medianas de las competencias de los alumnos de primer curso de Comunicación Audiovisual y tercer curso de Periodismo en este indicador de uso de competencia. 
TABla 7. CREAR Bases de DATOS

\begin{tabular}{|c|c|c|c|c|c|}
\hline \multicolumn{6}{|c|}{ INDICADOR: Creo bases de datos } \\
\hline Titulación. Curso & \multicolumn{5}{|c|}{ Valoración. Cuestionarios válidos } \\
\hline \multirow{4}{*}{$\begin{array}{c}\text { Comunicación } \\
\text { Audiovisual. } \\
1 .{ }^{\text {er }} \text { Curso }\end{array}$} & Valores & Frecuencia & Porcentaje & $\begin{array}{c}\text { Porcentaje } \\
\text { válido }\end{array}$ & $\begin{array}{c}\text { Porcentaje } \\
\text { acumulado }\end{array}$ \\
\cline { 2 - 6 } & Nada & 22 & 36,7 & 36,7 & 36,7 \\
\cline { 2 - 6 } & Algo & 17 & 28,3 & 28,3 & 65,0 \\
\cline { 2 - 6 } & Bastante & 5 & 8,3 & 8,3 & 73,3 \\
\cline { 2 - 6 } & Mucho & 12 & 20,0 & 20,0 & 93,3 \\
\cline { 2 - 6 } & Muchísimo & 4 & 6,7 & 6,7 & 100,0 \\
\cline { 2 - 6 } & Total & 60 & 100,0 & 100,0 & \\
\hline \multirow{4}{*}{$\begin{array}{c}\text { Periodismo. } \\
\text { er Curso }\end{array}$} & Nada & 11 & 18,3 & 18,3 & 18,3 \\
\cline { 2 - 6 } & Algo & 25 & 41,7 & 41,7 & 60,0 \\
\cline { 2 - 6 } & Bastante & 11 & 18,3 & 18,3 & 78,3 \\
\cline { 2 - 6 } & Mucho & 10 & 16,7 & 16,7 & 95,0 \\
\cline { 2 - 6 } & Muchísimo & 3 & 5,0 & 5,0 & 100,0 \\
\cline { 2 - 6 } & Total & 60 & 100,0 & 100,0 & \\
\hline
\end{tabular}

TABla 8. DOMinar ESTRATEgIAS DE BúSQUeda DE INFORMACióN

\begin{tabular}{|c|c|c|c|c|c|}
\hline \multicolumn{6}{|c|}{ INDICADOR: Domino estrategias de búsqueda de información } \\
\hline Titulación. Curso & \multicolumn{5}{|c|}{ Valoración. Cuestionarios válidos } \\
\hline \multirow{4}{*}{$\begin{array}{c}\text { Comunicación } \\
\text { Audiovisual. } \\
\text { 1. }{ }^{\text {Cr Curso }}\end{array}$} & Valores & Frecuencia & Porcentaje & $\begin{array}{c}\text { Porcentaje } \\
\text { válido }\end{array}$ & $\begin{array}{c}\text { Porcentaje } \\
\text { acumulado }\end{array}$ \\
\cline { 2 - 6 } & Nada & - & - & - & - \\
\cline { 2 - 6 } & Algo & 15 & 25,0 & 25,0 & 25,0 \\
\cline { 2 - 6 } & Bastante & 13 & 21,7 & 21,7 & 46,7 \\
\cline { 2 - 6 } & Mucho & 22 & 36,7 & 36,7 & 83,3 \\
\cline { 2 - 6 } & Muchísimo & 10 & 16,7 & 16,7 & 100,0 \\
\cline { 2 - 6 } & Total & 60 & 100,0 & 100,0 & \\
\hline \multirow{4}{*}{$\begin{array}{c}\text { Periodismo. } \\
\text { er Curso }\end{array}$} & Nada & 5 & 8,3 & 8,3 & 8,3 \\
\cline { 2 - 6 } & Algo & 12 & 20,0 & 20,0 & 28,3 \\
\cline { 2 - 6 } & Bastante & 10 & 16,7 & 16,7 & 45,0 \\
\cline { 2 - 6 } & Mucho & 14 & 23,3 & 23,3 & 68,3 \\
\cline { 2 - 6 } & Muchísimo & 19 & 31,7 & 31,7 & 100,0 \\
\cline { 2 - 6 } & Total & 60 & 100,0 & 100,0 & \\
\hline
\end{tabular}


Los estudiantes usan este indicador con dificultad (Tabla 7). Treinta y nueve estudiantes de Comunicación Audiovisual declaran usarlo solamente (nada+algo). En el extremo contrario, dieciséis, responden usarlo (mucho+muchísimo). Comparados con sus compañeros de Periodismo, treinta y seis estudiantes de esta titulación responden (nada+algo) y trece lo hacen en la escala (mucho+muchísimo). Sumando las frecuencias de uso catalogadas como bastante, mucho y muchísimo de ambos grupos - por separado- puede concluirse que ambos grupos usan este indicador de competencia con dificultad con valores porcentuales del 35\% y el 40\% respectivamente por lo que sería muy conveniente que ambos grupos adquirieran esta formación.

No todos los estudiantes usan este indicador de uso de competencia (Tabla 8) y los que lo hacen lo ejecutan en proporciones muy diferentes. No hay ningún estudiante de Comunicación Audiovisual que declare no usarlo nada aunque hay quince que lo usan solamente algo. En el extremo contrario, treinta y dos, responden usarlo (mucho+muchísimo) frente a cinco estudiantes de Periodismo que responden no usarlo nunca, doce que señalan usarlo algo y veintitrés que contestan usarlo (mucho+muchísimo).

Sumando las frecuencias de uso catalogadas como bastante, mucho y muchísimo de ambos grupos - por separado- puede concluirse que ambos grupos usan este indicador de competencia de manera notable con valores porcentuales del $75,1 \%$ y el $71,7 \%$ respectivamente por lo que ninguno de los grupos precisa formación sobre este indicador de uso de competencia.

\section{TABla 9. DOMINIO DE SISTEMAS AVANZADOS EN LA BÚSQUEDA DE INFORMACiÓN}

\begin{tabular}{|c|c|c|c|c|c|}
\hline Titulación. Curso & \multicolumn{5}{|c|}{ Valoración. Cuestionarios válidos } \\
\hline \multirow{7}{*}{$\begin{array}{l}\text { Comunicación } \\
\text { Audiovisual. } \\
1 \text { er }^{\text {er }} \text { Curso }\end{array}$} & Valores & Frecuencia & Porcentaje & $\begin{array}{c}\text { Porcentaje } \\
\text { válido }\end{array}$ & $\begin{array}{l}\text { Porcentaje } \\
\text { acumulado }\end{array}$ \\
\hline & Nada & 11 & 18,3 & 18,3 & 18,3 \\
\hline & Algo & 22 & 36,7 & 36,7 & 55,0 \\
\hline & Bastante & 14 & 23,3 & 23,3 & 78,3 \\
\hline & Mucho & 8 & 13,3 & 13,3 & 91,7 \\
\hline & Muchísimo & 5 & 8,3 & 8,3 & 100,0 \\
\hline & Total & 60 & 100,0 & 100,0 & \\
\hline \multirow{6}{*}{$\begin{array}{c}\text { Periodismo. } \\
3 \text {. }^{\text {re }} \text { Curso }\end{array}$} & Nada & 13 & 21,7 & 21,7 & 21,7 \\
\hline & Algo & 14 & 23,3 & 23,3 & 45,0 \\
\hline & Bastante & 21 & 35,0 & 35,0 & 80,0 \\
\hline & Mucho & 8 & 13,3 & 13,3 & 93,3 \\
\hline & Muchísimo & 4 & 6,7 & 6,7 & 100,0 \\
\hline & Total & 60 & 100,0 & 100,0 & \\
\hline
\end{tabular}


Este indicador de uso de competencia (Tabla 9) resulta fundamental entre los estudiantes de este campo de conocimiento con independencia de la titulación que estén cursando. Los resultados obtenidos en esta exploración llaman la atención puesto que treinta y tres estudiantes de Comunicación Audiovisual declaran usarlo solamente (nada+algo). En el extremo contrario, trece, responden usarlo (mucho+muchísimo) frente a veintisiete estudiantes de Periodismo que responden (nada+algo) y doce que lo hacen en la escala (mucho+muchísimo). Sumando las frecuencias de uso catalogadas como bastante, mucho y muchísimo de ambos grupos - por separado- puede concluirse que ambos grupos usan este indicador de competencia de manera suficiente pero con valores muy bajos. Sus valores porcentuales son del $44,9 \%$ y el $55 \%$ respectivamente. En los valores extremos superiores los estudiantes de Periodismo declaran usar el indicador de uso en menor proporción que los estudiantes de Comunicación Audiovisual (titulación menos cercana a esta utilidad que Periodismo).

Los estudiantes declaran utilizar este indicador de uso de forma desigual (Tabla 10). Quince estudiantes de Comunicación Audiovisual declaran usarlo solamente (nada+algo). En el extremo contrario, veintiocho, responden usarlo (mucho+muchísimo) frente a once estudiantes de Periodismo que responden (nada+algo) y treinta y cinco que lo hacen en la escala (mucho+muchísimo). Sumando las frecuencias de uso catalogadas como bastante, mucho y muchísimo de ambos grupos - por separado- puede concluirse que ambos grupos usan este indicador de competencia de forma notable pero desigual con valores porcentuales del 75\% y el $816 \%$ respectivamente por lo que ninguno de los grupos precisa formación sobre este indicador de uso de competencia.

Este indicador de uso de competencia (Tabla 11) es otro de los indicadores de uso que resulta fundamental para medir la capacitación inicial en el conocimiento de medios informáticos entre los estudiantes que inician la titulación de Comunicación Audiovisual. Los resultados obtenidos en esta exploración llaman la atención puesto que treinta y dos estudiantes de Comunicación Audiovisual declaran usarlo solamente (nada+algo). En el extremo contrario, diecinueve, responden usarlo (mucho+muchísimo) frente a treinta y ocho estudiantes de Periodismo que responden (nada+algo) y once que lo hacen en la escala (mucho+muchísimo). Sumando las frecuencias de uso catalogadas como bastante, mucho y muchísimo de ambos grupos - por separado- puede concluirse que ambos grupos usan este indicador de competencia de manera deficiente con valores porcentuales del 36,7\% y el 36,6\% respectivamente. Es más llamativo el resultado obtenido al comprobarse que los estudiantes de Periodismo superan en indicador de uso a los estudiantes de Comunicación Audiovisual (titulación más cercana a esta utilidad que Periodismo). 
INDICADORES DEL USO DE COMPETENCIAS INFORMÁTICAS ENTRE ESTUDIANTES UNIVERSITARIOS

TABla 10. MANEJO DE CÁMARAS

\begin{tabular}{|c|c|c|c|c|c|}
\hline \multicolumn{6}{|c|}{ INDICADOR: Utilizo cámaras de vídeo y fotografía para obtener recursos audiovisuales de calidad } \\
\hline Titulación. Curso & \multicolumn{5}{|c|}{ Valoración. Cuestionarios válidos } \\
\hline \multirow{4}{*}{$\begin{array}{c}\text { Comunicación } \\
\text { Audiovisual. } \\
\text { 1. }{ }^{\text {er }} \text { Curso }\end{array}$} & Valores & Frecuencia & Porcentaje & $\begin{array}{c}\text { Porcentaje } \\
\text { válido }\end{array}$ & $\begin{array}{c}\text { Porcentaje } \\
\text { acumulado }\end{array}$ \\
\cline { 2 - 6 } & Nada & 9 & 15,0 & 15,0 & 15,0 \\
\cline { 2 - 6 } & Algo & 6 & 10,0 & 10,0 & 25,0 \\
\cline { 2 - 6 } & Bastante & 7 & 11,7 & 11,7 & 36,7 \\
\cline { 2 - 6 } & Mucho & 15 & 25,0 & 25,0 & 61,7 \\
\cline { 2 - 6 } & Muchísimo & 23 & 38,3 & 38,3 & 100,0 \\
\cline { 2 - 6 } & Total & 60 & 100,0 & 100,0 & \\
\hline \multirow{4}{*}{$\begin{array}{c}\text { Periodismo. } \\
\text { er Curso }\end{array}$} & Nada & 7 & 11,7 & 11,7 & 11,7 \\
\cline { 2 - 6 } & Algo & 4 & 6,7 & 6,7 & 18,3 \\
\cline { 2 - 6 } & Bastante & 14 & 23,3 & 23,3 & 41,7 \\
\cline { 2 - 6 } & Mucho & 18 & 30,0 & 30,0 & 71,7 \\
\cline { 2 - 6 } & Muchísimo & 17 & 28,3 & 28,3 & 100,0 \\
\cline { 2 - 6 } & Total & 60 & 100,0 & 100,0 & \\
\hline
\end{tabular}

TABla 11. COMPOSICIÓN DE SONIDOS CON EQuipos DE AUdiO

\begin{tabular}{|c|c|c|c|c|c|}
\hline \multicolumn{6}{|c|}{ INDICADOR: Utilizo equipos de audio para la realización y composición de sonidos } \\
\hline Titulación. Curso & \multicolumn{5}{|c|}{ Valoración. Cuestionarios válidos } \\
\hline \multirow{4}{*}{$\begin{array}{c}\text { Comunicación } \\
\text { Audiovisual. } \\
1 .{ }^{\text {er }} \text { Curso }\end{array}$} & Valores & Frecuencia & Porcentaje & $\begin{array}{c}\text { Porcentaje } \\
\text { válido }\end{array}$ & $\begin{array}{c}\text { Porcentaje } \\
\text { acumulado }\end{array}$ \\
\cline { 2 - 6 } & Nada & 16 & 26,7 & 26,7 & 26,7 \\
\cline { 2 - 6 } & Algo & 16 & 26,7 & 26,7 & 53,3 \\
\cline { 2 - 6 } & Bastante & 9 & 15,0 & 15,0 & 68,3 \\
\cline { 2 - 6 } & Mucho & 6 & 10,0 & 10,0 & 78,3 \\
\cline { 2 - 6 } & Muchísimo & 13 & 21,7 & 21,7 & 100,0 \\
\cline { 2 - 6 } & Total & 60 & 100,0 & 100,0 & \\
\hline \multirow{4}{*}{$\begin{array}{c}\text { Periodismo. } \\
3 .{ }^{\text {er }} \text { Curso }\end{array}$} & Nada & 14 & 23,3 & 23,3 & 23,3 \\
\cline { 2 - 6 } & Algo & 24 & 40,0 & 40,0 & 63,3 \\
\cline { 2 - 6 } & Bastante & 11 & 18,3 & 18,3 & 81,7 \\
\cline { 2 - 6 } & Mucho & 6 & 10,0 & 10,0 & 91,7 \\
\cline { 2 - 6 } & Muchísimo & 5 & 8,3 & 8,3 & 100,0 \\
\cline { 2 - 6 } & Total & 60 & 100,0 & 100,0 & \\
\hline
\end{tabular}


Los estudiantes usan este indicador de forma desigual (Tabla 12). Dieciocho estudiantes de Comunicación Audiovisual declaran usarlo solamente (nada+algo). En el extremo contrario, treinta y cuatro, responden usarlo (mucho+muchísimo) frente a veintitrés estudiantes de Periodismo que responden usarlo (nada+algo) y veintiséis que responden usarlo (mucho+muchísimo). Sumando las frecuencias de uso catalogadas como bastante, mucho y muchísimo de ambos grupos -por separado- puede concluirse que ambos grupos usan este indicador de competencia de manera desigual con valores porcentuales del 70\% y el 61,6\% respectivamente. Al aplicar la prueba no paramétrica de Mann-Whitney-Wilcoxon a las dos muestras estudiadas y tomando como variable de agrupación la edad de los sujetos estudiados, como se expondrá en otra parte del artículo, se observará que existen diferencias significativas entre las medianas de las competencias de los alumnos de primer curso de Comunicación Audiovisual y tercer curso de Periodismo en este indicador de uso de competencia.

TABla 12. UTILIZACIÓN DE IMÁGENES

\begin{tabular}{|c|c|c|c|c|c|}
\hline \multicolumn{6}{|c|}{ INDICADOR: Utilizo imágenes que previamente he editado } \\
\hline Titulación. Curso & & Valorac & Cuestionari & válidos & \\
\hline \multirow{7}{*}{$\begin{array}{l}\text { Comunicación } \\
\text { Audiovisual. } \\
1 .^{\text {er }} \text { Curso }\end{array}$} & Valores & Frecuencia & Porcentaje & $\begin{array}{c}\text { Porcentaje } \\
\text { válido }\end{array}$ & $\begin{array}{l}\text { Porcentaje } \\
\text { acumulado }\end{array}$ \\
\hline & Nada & 5 & 8,3 & 8,3 & 8,3 \\
\hline & Algo & 13 & 21,7 & 21,7 & 30,0 \\
\hline & Bastante & 8 & 13,3 & 13,3 & 43,3 \\
\hline & Mucho & 13 & 21,7 & 21,7 & 65,0 \\
\hline & Muchísimo & 21 & 35,0 & 35,0 & 100,0 \\
\hline & Total & 60 & 100,0 & 100,0 & \\
\hline \multirow{6}{*}{$\begin{array}{l}\text { Periodismo. } \\
3 \text { er }^{\text {er }} \text { Curso }\end{array}$} & $\mathrm{Nada}$ & 2 & 3,3 & 3,3 & 3,3 \\
\hline & Algo & 21 & 35,0 & 35,0 & 38,3 \\
\hline & Bastante & 11 & 18,3 & 18,3 & 56,7 \\
\hline & Mucho & 20 & 33,3 & 33,3 & 90,0 \\
\hline & Muchísimo & 6 & 10,0 & 10,0 & 100,0 \\
\hline & Total & 60 & 100,0 & 100,0 & \\
\hline
\end{tabular}


INDICADORES DEL USO DE COMPETENCIAS INFORMÁTICAS ENTRE ESTUDIANTES UNIVERSITARIOS

TABLA 13. ANIMAR OBJETOS

\begin{tabular}{|c|c|c|c|c|c|}
\hline \multicolumn{6}{|c|}{ INDICADOR: Utilizo animación de objetos } \\
\hline Titulación. Curso & \multicolumn{5}{|c|}{ Valoración. Cuestionarios válidos } \\
\hline \multirow{4}{*}{$\begin{array}{c}\text { Comunicación } \\
\text { Audiovisual. } \\
1{ }^{\text {er }} \text { Curso }\end{array}$} & Valores & Frecuencia & Porcentaje & $\begin{array}{c}\text { Porcentaje } \\
\text { válido }\end{array}$ & $\begin{array}{c}\text { Porcentaje } \\
\text { acumulado }\end{array}$ \\
\cline { 2 - 6 } & Nada & 23 & 38,3 & 38,3 & 38,3 \\
\cline { 2 - 6 } & Algo & 16 & 26,7 & 26,7 & 65,0 \\
\cline { 2 - 6 } & Bastante & 11 & 18,3 & 18,3 & 83,3 \\
\cline { 2 - 6 } & Mucho & 7 & 11,7 & 11,7 & 95,0 \\
\cline { 2 - 6 } & Muchísimo & 3 & 5,0 & 5,0 & 100,0 \\
\cline { 2 - 6 } & Total & 60 & 100,0 & 100,0 & \\
\hline \multirow{4}{*}{$\begin{array}{c}\text { Periodismo. } \\
3 .{ }^{\text {er }} \text { Curso }\end{array}$} & Nada & 27 & 45,0 & 45,0 & 45,0 \\
\cline { 2 - 6 } & Algo & 26 & 43,3 & 43,3 & 88,3 \\
\cline { 2 - 6 } & Bastante & 2 & 3,3 & 3,3 & 91,7 \\
\cline { 2 - 6 } & Mucho & 4 & 6,7 & 6,7 & 98,3 \\
\cline { 2 - 6 } & Muchísimo & 1 & 1,7 & 1,7 & 100,0 \\
\cline { 2 - 6 } & Total & 60 & 100,0 & 100,0 & \\
\hline
\end{tabular}

TABLA 14. MANEJAR INTERNET

\begin{tabular}{|c|c|c|c|c|c|}
\hline \multirow{2}{*}{ INDICADOR: Accedo y navego por Internet } \\
\hline Titulación. Curso & \multicolumn{5}{|c|}{ Valoración. Cuestionarios válidos } \\
\hline \multirow{4}{*}{$\begin{array}{c}\text { Comunicación } \\
\text { Audiovisual. } \\
1 .{ }^{\text {er }} \text { Curso }\end{array}$} & Valores & Frecuencia & Porcentaje & $\begin{array}{c}\text { Porcentaje } \\
\text { válido }\end{array}$ & $\begin{array}{c}\text { Porcentaje } \\
\text { acumulado }\end{array}$ \\
\cline { 2 - 6 } & Nada & - & - & - & - \\
\cline { 2 - 6 } & Algo & 2 & 3,3 & 3,3 & 3,3 \\
\cline { 2 - 6 } & Bastante & 5 & 8,3 & 8,3 & 11,7 \\
\cline { 2 - 6 } & Mucho & 10 & 16,7 & 16,7 & 28,3 \\
\cline { 2 - 6 } & Muchísimo & 43 & 71,7 & 71,7 & 100,0 \\
\cline { 2 - 6 } & Total & 60 & 100,0 & 100,0 & \\
\hline \multirow{4}{*}{$\begin{array}{c}\text { Periodismo. } \\
\text { er Curso }\end{array}$} & Nada & - & - & - & - \\
\cline { 2 - 6 } & Algo & - & - & - & 3,3 \\
\cline { 2 - 6 } & Bastante & 2 & 3,3 & 3,3 & 100,0 \\
\cline { 2 - 6 } & Mucho & 17 & 28,3 & 28,3 & \\
\cline { 2 - 6 } & Muchísimo & 41 & 68,3 & 68,3 & 100,0 \\
\cline { 2 - 6 } & Total & 60 & 100,0 & & \\
\hline
\end{tabular}


Los estudiantes usan este indicador de forma desigual (Tabla 13). Treinta y nueve estudiantes de Comunicación Audiovisual declaran usarlo solamente (nada+algo). En el extremo contrario, diez responden usarlo (mucho+muchísimo) frente a cincuenta y tres estudiantes de Periodismo que responden usarlo (nada+algo) y cinco que responden usarlo (mucho+muchísimo). Sumando las frecuencias de uso catalogadas como bastante, mucho y muchísimo de ambos grupos -por separado- puede concluirse que ambos grupos usan este indicador de competencia de manera desigual con valores porcentuales del 35\% y el 11,7\% respectivamente por lo que sería conveniente que ambos grupos ampliaran conocimientos de uso de esta competencia.

Todos los estudiantes usan este indicador aunque en proporciones diferentes (Tabla 14). Dos estudiantes de Comunicación Audiovisual declaran usarlo solamente algo. En el extremo contrario, cincuenta y tres responden usarlo (mucho+muchísimo) frente a cero estudiantes de Periodismo que responden no usarlo nada o usarlo algo y cincuenta y ocho que declaran usarlo (mucho+muchísimo). Sumando las frecuencias de uso catalogadas como bastante, mucho y muchísimo de ambos grupos - por separado- puede concluirse que ambos grupos usan este indicador de competencia de manera sobresaliente con valores porcentuales del $96,7 \%$ y el $100 \%$ respectivamente por lo que ninguno de los grupos precisa formación sobre este indicador de uso de competencia.

Todos los estudiantes usan este indicador (Tabla 15) aunque en proporciones diferentes. Once estudiantes de Comunicación Audiovisual declaran usarlo solamente algo. En el extremo contrario, cuarenta y tres responden usarlo (mucho+muchísimo). Entre los estudiantes de Periodismo cinco declaran usarlo algo y cuarenta y uno (mucho+muchísimo). Sumando las frecuencias de uso catalogadas como bastante, mucho y muchísimo de ambos grupos - por separado- puede concluirse que ambos grupos usan este indicador de competencia de manera sobresaliente con valores porcentuales del $81,6 \%$ y el $91,7 \%$ respectivamente por lo que ninguno de los grupos precisa formación sobre este indicador de uso de competencia.

Todos los estudiantes usan este indicador aunque en proporciones diferentes (Tabla 16). El valor mínimo que se declara utilizar es el de bastante. Así tres estudiantes de Comunicación Audiovisual indican usarlo bastante frente a siete estudiantes de Periodismo. En el extremo contrario, cincuenta y siete estudiantes de Comunicación Audiovisual responden usarlo (mucho+muchísimo) frente a cincuenta y tres estudiantes de Periodismo que responden en las mismas categorías. Sumando las frecuencias de uso catalogadas como bastante, mucho y muchísimo de ambos grupos - por separado- puede concluirse que ambos grupos usan este indicador de competencia de manera sobresaliente con valores porcentuales del $100 \%$ y el 100\% respectivamente por lo que ninguno de los grupos precisa formación sobre este indicador de uso de competencia. 
M. ${ }^{a}$ LUISA SEVILLANO GARCÍA Y M. ${ }^{a}$ DEL PILAR QUICIOS GARCÍA

INDICADORES DEL USO DE COMPETENCIAS INFORMÁTICAS ENTRE ESTUDIANTES UNIVERSITARIOS

TABla 15. CONOCER FUnCIONAMIENTO DE BUSCADORES

\begin{tabular}{|c|c|c|c|c|c|}
\hline \multicolumn{6}{|c|}{ INDICADOR: Conozco cómo funcionan diferentes buscadores } \\
\hline Titulación. Curso & \multicolumn{5}{|c|}{ Valoración. Cuestionarios válidos } \\
\hline \multirow{4}{*}{$\begin{array}{c}\text { Comunicación } \\
\text { Audiovisual. } \\
1 .{ }^{\text {er }} \text { Curso }\end{array}$} & Valores & Frecuencia & Porcentaje & $\begin{array}{c}\text { Porcentaje } \\
\text { válido }\end{array}$ & $\begin{array}{c}\text { Porcentaje } \\
\text { acumulado }\end{array}$ \\
\cline { 2 - 6 } & Nada & - & - & - & - \\
\cline { 2 - 6 } & Algo & 11 & 18,3 & 18,3 & 18,3 \\
\cline { 2 - 6 } & Bastante & 6 & 10,0 & 10,0 & 28,3 \\
\cline { 2 - 6 } & Mucho & 17 & 28,3 & 28,3 & 56,7 \\
\cline { 2 - 6 } & Muchísimo & 26 & 43,3 & 43,3 & 100,0 \\
\cline { 2 - 6 } & Total & 60 & 100,0 & 100,0 & \\
\hline \multirow{4}{*}{$\begin{array}{c}\text { Periodismo. } \\
\text { er Curso }\end{array}$} & Nada & - & - & - & - \\
\cline { 2 - 6 } & Algo & 5 & 8,3 & 8,3 & 8,3 \\
\cline { 2 - 6 } & Bastante & 14 & 23,3 & 23,3 & 58,3 \\
\cline { 2 - 6 } & Mucho & 16 & 26,7 & 26,7 & 100,0 \\
\cline { 2 - 6 } & Muchísimo & 25 & 41,7 & 41,7 & \\
\cline { 2 - 6 } & Total & 60 & 100,0 & 100,0 & \\
\hline
\end{tabular}

TABLA 16. UTILIZAR CORREO ELECRÓNICO

\begin{tabular}{|c|c|c|c|c|c|}
\hline \multirow{2}{*}{ INDICADOR: Utilizo el correo electrónico } \\
\hline Titulación. Curso & \multicolumn{5}{|c|}{ Valoración. Cuestionarios válidos } \\
\hline \multirow{4}{*}{$\begin{array}{c}\text { Comunicación } \\
\text { Audiovisual. } \\
1 .{ }^{\text {er }} \text { Curso }\end{array}$} & Valores & Frecuencia & Porcentaje & $\begin{array}{c}\text { Porcentaje } \\
\text { válido }\end{array}$ & $\begin{array}{c}\text { Porcentaje } \\
\text { acumulado }\end{array}$ \\
\cline { 2 - 6 } & Nada & - & - & - & - \\
\cline { 2 - 6 } & Algo & - & - & - & - \\
\cline { 2 - 6 } & Bastante & 3 & 5,0 & 5,0 & 5,0 \\
\cline { 2 - 6 } & Mucho & 12 & 20,0 & 20,0 & 25,0 \\
\cline { 2 - 6 } & Muchísimo & 45 & 75,0 & 75,0 & 100,0 \\
\cline { 2 - 6 } & Total & 60 & 100,0 & 100,0 & \\
\hline \multirow{4}{*}{$\begin{array}{c}\text { Periodismo. } \\
\text { er Curso }\end{array}$} & Nada & - & - & - & - \\
\cline { 2 - 6 } & Algo & - & - & - & 11,7 \\
\cline { 2 - 6 } & Bastante & 7 & 11,7 & 11,7 & 30,0 \\
\cline { 2 - 6 } & Mucho & 11 & 70,3 & 18,3 & 100,0 \\
\cline { 2 - 6 } & Muchísimo & 42 & 70,0 & 70,0 & \\
\cline { 2 - 6 } & Total & 60 & 100,0 & 100,0 & \\
\hline
\end{tabular}


M. ${ }^{a}$ LUISA SEVILLANO GARCÍA Y M. ${ }^{a}$ DEL PILAR QUICIOS GARCÍA

INDICADORES DEL USO DE COMPETENCIAS INFORMÁTICAS ENTRE ESTUDIANTES UNIVERSITARIOS

TABla 17. DOMINIO EN ADJUNTAR ARCHIVOS

\begin{tabular}{|c|c|c|c|c|c|}
\hline \multicolumn{6}{|c|}{ INDICADOR: Adjunto archivos } \\
\hline Titulación. Curso & & Valoraci & Cuestionar & válidos & \\
\hline \multirow{7}{*}{$\begin{array}{c}\text { Comunicación } \\
\text { Audiovisual. } \\
1 .^{\mathrm{er}} \text { Curso }\end{array}$} & Valores & Frecuencia & Porcentaje & $\begin{array}{c}\text { Porcentaje } \\
\text { válido }\end{array}$ & $\begin{array}{l}\text { Porcentaje } \\
\text { acumulado }\end{array}$ \\
\hline & Nada & - & - & - & - \\
\hline & Algo & 4 & 6,7 & 6,7 & 6,7 \\
\hline & Bastante & 6 & 10,0 & 10,0 & 16,7 \\
\hline & Mucho & 12 & 20,0 & 20,0 & 36,7 \\
\hline & Muchísimo & 38 & 63,3 & 63,3 & 100,0 \\
\hline & Total & 60 & 100,0 & 100,0 & \\
\hline \multirow{6}{*}{$\begin{array}{l}\text { Periodismo. } \\
3 .{ }^{\text {er }} \text { Curso }\end{array}$} & Nada & - & - & - & - \\
\hline & Algo & - & - & - & - \\
\hline & Bastante & 14 & 23,3 & 23,3 & 23,3 \\
\hline & Mucho & 9 & 15,0 & 15,0 & 38,3 \\
\hline & Muchísimo & 37 & 61,7 & 61,7 & 100,0 \\
\hline & Total & 60 & 100,0 & 100,0 & \\
\hline
\end{tabular}

Todos los estudiantes usan este indicador aunque lo hagan de forma desigual (Tabla 17). Cuatro estudiantes de Comunicación Audiovisual declaran usarlo solamente algo. En el extremo contrario, cincuenta responden usarlo (mucho+muchísimo) frente a cuarenta y seis estudiantes de Periodismo que responden en las mismas categorías. Sumando las frecuencias de uso catalogadas como bastante, mucho y muchísimo de ambos grupos - por separado- puede concluirse que ambos grupos usan este indicador de competencia de manera sobresaliente con valores porcentuales del $93,3 \%$ y el 100\% respectivamente por lo que ninguno de los grupos precisa formación sobre este indicador de uso de competencia.

Los estudiantes usan este indicador (Tabla 18) de forma desigual. Ocho estudiantes de Comunicación Audiovisual declaran usarlo solamente (nada+algo). En el extremo contrario, cuarenta y seis responden usarlo (mucho+muchísimo) frente a cuatro de Periodismo que responden algo y cuarenta y nueve que responden (mucho+muchísimo). Sumando las frecuencias de uso catalogadas como bastante, mucho y muchísimo de ambos grupos - por separado- puede concluirse que ambos grupos usan este indicador de competencia de manera notable con valores porcentuales del $86,6 \%$ y el $93,4 \%$ respectivamente por lo que ninguno de los grupos precisa formación sobre este indicador de uso de competencia. 
INDICADORES DEL USO DE COMPETENCIAS INFORMÁTICAS ENTRE ESTUDIANTES UNIVERSITARIOS

\section{TABLA 18. USAR FOROS}

\begin{tabular}{|c|c|c|c|c|c|}
\hline \multicolumn{6}{|c|}{ INDICADOR: Me comunico en foros de discusión } \\
\hline Titulación. Curso & & Valora & Cuestionar & válidos & \\
\hline \multirow{7}{*}{$\begin{array}{c}\text { Comunicación } \\
\text { Audiovisual. } \\
1 .^{\text {er }} \text { Curso }\end{array}$} & Valores & Frecuencia & Porcentaje & $\begin{array}{c}\text { Porcentaje } \\
\text { válido }\end{array}$ & $\begin{array}{l}\text { Porcentaje } \\
\text { acumulado }\end{array}$ \\
\hline & $\mathrm{Nada}$ & 2 & 3,3 & 3,3 & 3,3 \\
\hline & Algo & 6 & 10,0 & 10,0 & 13,3 \\
\hline & Bastante & 6 & 10,0 & 10,0 & 23,3 \\
\hline & Mucho & 8 & 13,3 & 13,3 & 36,7 \\
\hline & Muchísimo & 38 & 63,3 & 63,3 & 100,0 \\
\hline & Total & 60 & 100,0 & 100,0 & \\
\hline \multirow{6}{*}{$\begin{array}{l}\text { Periodismo. } \\
3 \text {.r }^{\text {er }} \text { Curso }\end{array}$} & Nada & - & - & - & - \\
\hline & Algo & 4 & 6,7 & 6,7 & 6,7 \\
\hline & Bastante & 7 & 11,7 & 11,7 & 18,3 \\
\hline & Mucho & 12 & 20,0 & 20,0 & 38,3 \\
\hline & Muchísimo & 37 & 61,7 & 61,7 & 100,0 \\
\hline & Total & 60 & 100,0 & 100,0 & \\
\hline
\end{tabular}

\section{TABLA 19. UTILIZAR CHAT}

\begin{tabular}{|c|c|c|c|c|c|}
\hline \multicolumn{6}{|c|}{ INDICADOR: Utilizo chat } \\
\hline Titulación. Curso & & Valorac & Cuestionar & válidos & \\
\hline \multirow{7}{*}{$\begin{array}{c}\text { Comunicación } \\
\text { Audiovisual. } \\
1 .^{\mathrm{er}} \text { Curso }\end{array}$} & Valores & Frecuencia & Porcentaje & $\begin{array}{c}\text { Porcentaje } \\
\text { válido }\end{array}$ & $\begin{array}{l}\text { Porcentaje } \\
\text { acumulado }\end{array}$ \\
\hline & Nada & - & - & - & - \\
\hline & Algo & 3 & 5,0 & 5,0 & 5,0 \\
\hline & Bastante & 9 & 15,0 & 15,0 & 20,0 \\
\hline & Mucho & 11 & 18,3 & 18,3 & 38,3 \\
\hline & Muchísimo & 37 & 61,7 & 61,7 & 100,0 \\
\hline & Total & 60 & 100,0 & 100,0 & \\
\hline \multirow{6}{*}{$\begin{array}{c}\text { Periodismo. } \\
3 \text { er }^{\text {er }} \text { Curso }\end{array}$} & Nada & - & - & - & - \\
\hline & Algo & 6 & 10,0 & 10,0 & 10,0 \\
\hline & Bastante & 3 & 5,0 & 5,0 & 15,0 \\
\hline & Mucho & 13 & 21,7 & 21,7 & 36,7 \\
\hline & Muchísimo & 38 & 63,3 & 63,3 & 100,0 \\
\hline & Total & 60 & 100,0 & 100,0 & \\
\hline
\end{tabular}


Todos los estudiantes declaran utilizar este indicador de uso de competencia informática (Tabla 19) aunque con una frecuencia de uso desigual. Tres estudiantes de Comunicación Audiovisual declaran usarlo algo frente a seis estudiantes de Periodismo que manifiestan usarlo algo. En el extremo contrario, cuarenta y ocho estudiantes de Comunicación Audiovisual responden usarlo (mucho+muchísimo) frente a cincuenta y un estudiantes de Periodismo que responden (mucho+muchísimo). Sumando las frecuencias de uso catalogadas como bastante, mucho y muchísimo de ambos grupos - por separado- puede concluirse que ambos grupos usan este indicador de competencia de manera notable con valores porcentuales del 95\% y el 90\% respectivamente por lo que ninguno de los grupos precisa formación sobre este indicador de uso de competencia.

Los resultados obtenidos (Tabla 20) en esta exploración llaman la atención puesto que cuarenta y cuatro estudiantes de Comunicación Audiovisual declaran usar este indicador de uso de competencia con valores (nada+algo). En el extremo contrario, nueve responden usarlo (mucho+muchísimo) frente a veintiocho estudiantes de Periodismo que responden (nada+algo) y diecinueve que lo hacen en la escala (mucho+muchísimo). Sumando las frecuencias de uso catalogadas como bastante, mucho y muchísimo de ambos grupos -por separado- puede concluirse que ambos grupos usan este indicador de competencia de manera deficiente con valores porcentuales del 26,7\% y el 53,4\% respectivamente. Al aplicar la prueba no paramétrica de Mann-Whitney-Wilcoxon a las dos muestras estudiadas y tomando como variable de agrupación la edad de los sujetos estudiados, como se expondrá en otra parte del artículo, se observará que existen diferencias significativas entre las medianas de las competencias de los alumnos de primer curso de Comunicación Audiovisual y tercer curso de Periodismo en este indicador de uso de competencia.

Los estudiantes responden usar este indicador de forma desigual (Tabla 21). Cuarenta y tres estudiantes de Comunicación Audiovisual declaran usarlo solamente (nada+algo). En el extremo contrario, nueve responden usarlo (mucho+muchísimo) frente a treinta y un estudiantes de Periodismo que responden (nada+algo) y veintiuno (mucho+muchísimo). Sumando las frecuencias de uso catalogadas como bastante, mucho y muchísimo de ambos grupos - por separado- puede concluirse que ambos grupos usan este indicador de competencia de manera desigual con valores porcentuales del $28,3 \%$ y el $48,3 \%$ respectivamente por lo que el grupo de Comunicación Audiovisual necesitaría formación sobre este indicador de uso de competencia. Al aplicar la prueba no paramétrica de Mann-Whitney-Wilcoxon a las dos muestras estudiadas y tomando como variable de agrupación la edad de los sujetos estudiados, como se expondrá en otra parte del artículo, se observará que existen diferencias significativas entre las medianas de las competencias de los alumnos de primer curso de Comunicación Audiovisual y tercer curso de Periodismo en este indicador de uso de competencia. 
INDICADORES DEL USO DE COMPETENCIAS INFORMÁTICAS ENTRE ESTUDIANTES UNIVERSITARIOS

TABla 20. MANEJO DE LISTAS DE DisTRIBUCIÓN

\begin{tabular}{|c|c|c|c|c|c|}
\hline \multicolumn{6}{|c|}{ INDICADOR: Utilizo listas de distribución } \\
\hline Titulación. Curso & \multicolumn{5}{|c|}{ Valoración. Cuestionarios válidos } \\
\hline \multirow{4}{*}{$\begin{array}{c}\text { Comunicación } \\
\text { Audiovisual. } \\
\text { 1. }{ }^{\text {er }} \text { Curso } \\
\end{array}$} & Valores & Frecuencia & Porcentaje & $\begin{array}{c}\text { Porcentaje } \\
\text { válido }\end{array}$ & $\begin{array}{c}\text { Porcentaje } \\
\text { acumulado }\end{array}$ \\
\cline { 2 - 6 } & Nada & 26 & 43,3 & 43,3 & 43,3 \\
\cline { 2 - 6 } & Algo & 18 & 30,0 & 30,0 & 73,3 \\
\cline { 2 - 6 } & Bastante & 7 & 11,7 & 11,7 & 85,0 \\
\cline { 2 - 6 } & Mucho & 4 & 6,7 & 6,7 & 91,7 \\
\cline { 2 - 6 } & Muchísimo & 5 & 8,3 & 8,3 & 100,0 \\
\cline { 2 - 6 } & Total & 60 & 100,0 & 100,0 & \\
\hline \multirow{4}{*}{$\begin{array}{c}\text { Periodismo. } \\
\text { er Curso }\end{array}$} & Nada & 12 & 20,0 & 20,0 & 20,0 \\
\cline { 2 - 6 } & Algo & 16 & 26,7 & 26,7 & 46,7 \\
\cline { 2 - 6 } & Bastante & 13 & 21,7 & 21,7 & 68,3 \\
\cline { 2 - 6 } & Mucho & 12 & 20,0 & 20,0 & 88,3 \\
\cline { 2 - 6 } & Muchísimo & 7 & 11,7 & 11,7 & 100,0 \\
\cline { 2 - 6 } & Total & 60 & 100,0 & 100,0 & \\
\hline
\end{tabular}

TABla 21. Elaborar PÁGinas WeB

\begin{tabular}{|c|c|c|c|c|c|}
\hline \multicolumn{5}{|c|}{ INDICADOR: Elaboro páginas web } \\
\hline Titulación. Curso & \multicolumn{5}{|c|}{ Valoración. Cuestionarios válidos } \\
\hline \multirow{4}{*}{$\begin{array}{c}\text { Comunicación } \\
\text { Audiovisual. } \\
1 .{ }^{\text {er }} \text { Curso }\end{array}$} & Valores & Frecuencia & Porcentaje & $\begin{array}{c}\text { Porcentaje } \\
\text { válido }\end{array}$ & $\begin{array}{c}\text { Porcentaje } \\
\text { acumulado }\end{array}$ \\
\cline { 2 - 6 } & Nada & 26 & 43,3 & 43,3 & 43,3 \\
\cline { 2 - 6 } & Algo & 17 & 28,3 & 28,3 & 71,7 \\
\cline { 2 - 6 } & Bastante & 8 & 13,3 & 13,3 & 85,0 \\
\cline { 2 - 6 } & Mucho & 2 & 3,3 & 3,3 & 88,3 \\
\cline { 2 - 6 } & Muchísimo & 7 & 11,7 & 11,7 & 100,0 \\
\cline { 2 - 6 } & Total & 60 & 100,0 & 100,0 & \\
\hline \multirow{4}{*}{$\begin{array}{c}\text { Periodismo. } \\
\text { er }{ }^{\text {er }} \text { Curso }\end{array}$} & Nada & 20 & 33,3 & 33,3 & 33,3 \\
\cline { 2 - 6 } & Algo & 11 & 18,3 & 18,3 & 51,7 \\
\cline { 2 - 6 } & Bastante & 8 & 13,3 & 13,3 & 65,0 \\
\cline { 2 - 6 } & Mucho & 11 & 18,3 & 18,3 & 83,3 \\
\cline { 2 - 6 } & Muchísimo & 10 & 16,7 & 16,7 & 100,0 \\
\cline { 2 - 6 } & Total & 60 & 100,0 & 100,0 & \\
\hline
\end{tabular}


M. ${ }^{a}$ LUISA SEVILLANO GARCÍA Y M. ${ }^{a}$ DEL PILAR QUICIOS GARCÍA

INDICADORES DEL USO DE COMPETENCIAS INFORMÁTICAS ENTRE ESTUDIANTES UNIVERSITARIOS

5. Prueba de Mann-Whitney-Wilcoxom

Para comprobar la heterogeneidad de las dos muestras ordinales se aplicó la prueba no paramétrica de Mann-Whitney-Wilcoxon para dos muestras independientes.

TABla 22. HETEROGENEIDAD EN DOS MUESTRAS ORDINALES

\begin{tabular}{|c|c|c|c|c|}
\hline $\begin{array}{c}\text { Estadísticos } \\
\text { de Contraste }\end{array}$ & $\begin{array}{c}\text { Realizo gráficos } \\
\text { a partir de datos }\end{array}$ & $\begin{array}{c}\text { Utilizo imágenes } \\
\text { que previamente } \\
\text { he editado }\end{array}$ & $\begin{array}{c}\text { Utilizo listas de } \\
\text { distribución }\end{array}$ & $\begin{array}{c}\text { Elaboro } \\
\text { páginas web }\end{array}$ \\
\hline U de Mann-Whitney & $1.304,000$ & $1.435,500$ & $1.228,000$ & $1.447,500$ \\
\hline W de Wilcoxon & $3.134,000$ & $3.265,500$ & $3.058,000$ & $3.277,500$ \\
\hline Z & $-2,700$ & $-1,972$ & $-3,101$ & $-1,924$ \\
\hline $\begin{array}{c}\text { Sig. Asintót. } \\
\text { (bilateral) }\end{array}$ &, 007 &, 049 &, 002 &, 054 \\
\hline
\end{tabular}

La variable agrupación de edad fue la variable tomada en consideración. Con esta prueba se quiso analizar la existencia o inexistencia de diferencias significativas entre los dos grupos de estudiantes encuestados. Para conseguir estos resultados se comprobaron los valores de Sig. Asintót. a la probabilidad del valor U de Mann-Whitney, calculado anteriormente, correspondieron respectivamente los valores 0,007, 0,049 y 0,002. Todos estos valores, menores que el nivel de significatividad 0,05 . Por ello puede afirmarse que existen diferencias significativas entre las medianas de los indicadores de uso de las competencias en los siguientes ítems:

- Realizo gráficos a partir de datos.

- Utilizo imágenes que previamente he editado.

- Utilizo listas de distribución.

- Elaboro páginas web.

\section{Algunos Resultados del estudio cualitativo}

\subsection{Respuestas a la pregunta veintisiete del cuestionario}

La pregunta 27 del cuestionario es de naturaleza cualitativa por lo que se contesta con una frase explicativa. Esta pregunta es una cuestión cualitativa de respuesta abierta. Con este ítem se pretendió sacar a luz las carencias formativas que cada uno de los estudiantes encuestados creía poseer. Para ello se les solicitaba que indicasen tanto qué creen que deberían saber para ser más competentes informáticamente como cuál creen que es la naturaleza de su carencia formativa. Las respuestas emitidas se recogen en los siguientes apartados. 
INDICADORES DEL USO DE COMPETENCIAS INFORMÁTICAS ENTRE ESTUDIANTES UNIVERSITARIOS

Cuadro 2. Respuestas de los estudiantes de tercer Curso De Periodismo

\begin{tabular}{|c|c|c|}
\hline PROTOCOLO & RESPUESTA EMITIDA & CARENCIAS FORMATIVAS \\
\hline 1 & $\begin{array}{l}\text { Saber, conceptualmente, qué es una dirección } \\
\text { web y un correo electrónico }\end{array}$ & Instrucción \\
\hline 3 & Utilización básica del ordenador & Saber hacer (Capacitación) \\
\hline 3 & $\begin{array}{l}\text { Saber definir y encontrar, de forma óptima y } \\
\text { breve, la información deseada }\end{array}$ & $\begin{array}{c}\text { Saber (Instrucción) + Saber } \\
\text { hacer (Capacitación) }\end{array}$ \\
\hline 4 & $\begin{array}{l}\text { Conocer los rudimentos básicos para desenvolverse } \\
\text { en Office }\end{array}$ & Saber (Instrucción) \\
\hline $4 \mathrm{y} 7$ & Saber utilizar navegadores & Saber hacer (Capacitación) \\
\hline 6 y 19 & Hacer cursos básicos de informática & $\begin{array}{c}\text { Saber (Instrucción) }+ \text { Saber } \\
\text { hacer (Capacitación) }\end{array}$ \\
\hline 8 & $\begin{array}{l}\text { Conocer, primeramente, en qué se basan los } \\
\text { programas informáticos. Posteriormente investigar } \\
\text {-a base de ensayos- cómo funcionan los } \\
\text { programas o realizar un curso de informática }\end{array}$ & $\begin{array}{l}\text { Saber (Instrucción) + Saber } \\
\text { hacer (Capacitación) }\end{array}$ \\
\hline 17 & $\begin{array}{l}\text { Conocer cómo funcionan estos medios. Conocer } \\
\text { las distintas utilidades y programas }\end{array}$ & $\begin{array}{c}\text { Saber (Instrucción) }+ \text { Saber } \\
\text { hacer (Capacitación) }\end{array}$ \\
\hline 24 & $\begin{array}{l}\text { Saber manejar el ordenador } \\
\text { Saber crear una cuenta e intercambiar información } \\
\text { con gente que tenga otras cuentas }\end{array}$ & $\begin{array}{l}\text { Saber (Instrucción) + Saber } \\
\text { hacer (Capacitación) }\end{array}$ \\
\hline 30 & Conocer el idioma utilizado por los ordenadores & Saber (Instrucción) \\
\hline
\end{tabular}

Estas respuestas y otras similares fueron las expresadas de manera más unánime. Algunos estudiantes manifestaron, explícitamente, su autodidactismo apostando en unos casos por él y en otros mostrando sus limitaciones. Sus respuestas fueron: El saber ser y el saber estar, elementos igual de importantes que el resto de los componentes de cualquier competencia, no han aparecido entre las preocupaciones expresadas. Esta ausencia demuestra que las tecnologías y las herramientas virtuales -asumiendo la idea de García del Dujo (2009) - se han usado, exclusivamente, como espacio de información. Una vez más, se ha caído en el didactismo y la instrucción telemática olvidándose de los aspectos formativos, educacionales y/o relacionales. 
6.1.1. Algunas respuestas de los estudiantes de primer curso de Comunicación Audiovisual

Los estudiantes de primer curso de Comunicación Audiovisual respondieron la pregunta 27 así:

\section{CuAdro 3. ¿Qué DeBen SABER?}

\begin{tabular}{|c|l|c|}
\hline PROTOCOLO & \multicolumn{1}{|c|}{ RESPUESTA EMITIDA } & CARENCIAS FORMATIVAS \\
\hline 1 & $\begin{array}{l}\text { Conocimientos de informática básica: Internet, } \\
\text { Correo, hojas de cálculo }\end{array}$ & Saber (Instrucción) \\
\hline 2 & Ofimática sencilla & $\begin{array}{c}\text { Saber (Instrucción) } \\
\text { hacer (Capacitación) }\end{array}$ \\
\hline 3 & Conocimientos de e-mail y chat & $\begin{array}{c}\text { Saber (Instrucción) + Saber } \\
\text { hacer (Capacitación) }\end{array}$ \\
\hline 5 & No tengo conocimiento de listas de distribución \\
\hline 9 & $\begin{array}{l}\text { Conocer, al menos básicamente, los 26 puntos } \\
\text { del cuestionario }\end{array}$ & $\begin{array}{c}\text { Saber (Instrucción) + Saber } \\
\text { hacer (Capacitación) }\end{array}$ \\
\hline 12 & $\begin{array}{l}\text { Se precisan conocimientos básicos del } \\
\text { ordenador: manejo del teclado, ratón, pantalla, } \\
\text { cómo hacer columnas, pies de página, la barra } \\
\text { de herramientas }\end{array}$ & $\begin{array}{c}\text { Saber (Instrucción) + Saber } \\
\text { hacer (Capacitación) }\end{array}$ \\
\hline 18 & $\begin{array}{l}\text { Hacer un curso sobre todos estos medios } \\
\text { Saber (Instrucción) + Saber } \\
\text { hacer (Capacitación) }\end{array}$ \\
\hline
\end{tabular}

Éste es el estilo de respuestas que se encuentra en todos los protocolos.

\subsection{Respuestas a la pregunta treinta del cuestionario}

La pregunta 30 del cuestionario, también, se contesta a través de una respuesta abierta. Su contenido se centra en visualizar las dificultades que encuentran los estudiantes para alcanzar las competencias necesarias para el uso de las herramientas virtuales. Los estudiantes de tercer curso de Periodismo la respondieron indicando: 
INDICADORES DEL USO DE COMPETENCIAS INFORMÁTICAS ENTRE ESTUDIANTES UNIVERSITARIOS

6.2.1. Algunas respuestas de los estudiantes de primer curso de Comunicación Audiovisual

CuAdro 4. Dificultades EN El uSO DE HerRAmiEnTAS ViRTUALES

\begin{tabular}{|c|l|}
\hline PROTOCOLO & \multicolumn{1}{|c|}{ RESPUESTA EMITIDA } \\
\hline 1 & Si no se saben manejar los buscadores no se encuentra lo que se busca \\
\hline 3 & Zonas de interés restringidas, falta de software adecuado \\
\hline 7 & $\begin{array}{l}\text { Escasa seguridad y control de la información vertida en la Red. E-mail y chats } \\
\text { pueden ser focos peligrosos }\end{array}$ \\
\hline 22 & Sobrecarga de información, brecha digital, páginas en otros idiomas \\
\hline
\end{tabular}

En ese caso no faltan las reflexiones de tipo educativo y relacional. Estas respuestas unen los dos extremos del artículo y explicitan la necesidad de poner límites educativos o relacionales al uso de las herramientas virtuales. A modo de ejemplo se recogen las siguientes respuestas: Se pierde mucho tiempo en los buscadores. Si no se conocen perfectamente no se encuentra lo que se busca (protocolo 2). La principal dificultad es que no existe seguridad (protocolo 14). Hay mucha gente buena por la Red, pero también alguna mala (protocolo 17). Falta de conocimientos específicos sobre cada una de las herramientas, sus utilidades y su funcionamiento (protocolo 20). Es fácil a nivel usuario, pero difícil especializarse (protocolo 23). Hay que estar siempre actualizado (protocolo 2). Nunca sabes realmente que la identidad de algo o alguien es la verdadera (protocolo 26). Tampoco entre estos estudiantes faltaron las reflexiones de tipo educativo y relacional. A modo de ejemplo se recogen las siguientes respuestas

\section{Cuadro 5. Dificultades de naturaleza ÉTica}

\begin{tabular}{|c|l|}
\hline PROTOCOLO & \multicolumn{1}{|c|}{ RESPUESTA EMITIDA } \\
\hline 6 & Algunos timos y peligros, hasta físicos, en los chats e Internet \\
\hline 5 & La inseguridad de no saber con quién te estás relacionando \\
\hline 9 & Falta de seguridad en algunos servidores \\
\hline
\end{tabular}




\section{CONClusiones}

La globalización comercial, los avances científicos y tecnológicos, los nuevos esquemas en la reorganización del trabajo, la diversidad y la movilidad de los mercados laborales, así como una apuesta por la individualización de los aprendizajes, el traspaso de más responsabilidades en el proceso a los aprendices, la vinculación de las enseñanzas al ejercicio profesional, la influencia empresarial en la reorganización de los estudios son algunos de los elementos que inciden en los planteamientos actuales del término, concepto y uso de competencias. Se acepta en la comunidad científica como una combinación de aptitudes, atributos y comportamientos vinculados a un ejercicio profesional exitoso, buscando transformar el conocimiento en acción. También como conjunto de saberes combinados, coordinados e integrados en una estructura intelectual basada en recursos personales y ambientales y la integración de conocimientos conceptuales, procedimentales y actitudinales. Tiene funciones cognitivas, técnicas, relacionales y afectivomorales y supone valores, actitudes, motivación, habilidades y destrezas.

El concepto de competencia virtual se reserva para la comprensión y conocimiento sobre naturaleza, función y posibilidades de las tecnologías propias de la sociedad de la información en situaciones cotidianas de la vida privada, social y profesional. Representa la permanente capacidad y condiciones fundamentales en el tratamiento y proceso de representación de y en las tecnologías virtuales que implican capacidades cognitivas, analíticas, evaluativas, reflexivas, orientadas a la acción crítica, creativa, constructiva. Deben buscar el desarrollo social, cognitivo, proceso de socialización y el trato con medios.

Las poblaciones estudiadas de forma exploratoria (jóvenes universitarios de 19 y 22 años) manifiestan demandas de formación sistemática en herramientas informáticas. Entendiendo la educación como una actividad compleja para formar personas profesionalmente competentes que han de saber y saber hacer, saber ser y saber estar, es preciso no solamente enseñar conocimientos. Los usuarios de TIC deben llegar a saber y dominar qué hacer. Deben preguntarse por qué hacen lo que hacen. Conocer las consecuencias globales, éticas, ambientales, saludables sostenibles de todo lo que hacen. Es decir, el consumidor de tecnología informática debe adquirir una formación completa que se distancie del tecnologicismo simplista.

El análisis comparado de indicadores de uso de competencias informáticas entre los dos grupos explorados pone de manifiesto que los alumnos de primer curso de Comunicación Audiovisual presentan una mayor competencia para los siguientes usos: instalación, configuración y mantenimiento de un sistema de red local. Utilización de cámaras de vídeo y fotografía digital, equipos de audio para la realización y composición de sonidos, animación de objetos, acceso y navegación por Internet, funcionamiento de buscadores para obtener recursos audiovisuales de calidad. 
En cuestiones que precisan formación específica para adquirir una determinada competencia informática les aventajan, de forma general, los estudiantes de tercero de Periodismo. Este hecho permite afirmar que no es, sólo, la edad cronológica la variable determinante de la competencia virtual, sino también la correcta alfabetización informática que se haya recibido.

Tanto los estudiantes de primer curso de Comunicación Audiovisual como los estudiantes de tercer curso de Periodismo han denotado cierta carencia formativa en los siguientes indicadores de uso de competencias informáticas, realización de la instalación, configuración y mantenimiento de un sistema de red local, creación de bases de datos y utilización de animación de objetos.

Los estudiantes de primer curso de Comunicación Audiovisual, de forma aislada, han demostrado carencias formativas en la realización de gráficos a partir de datos y en la elaboración de páginas web mientras que los estudiantes de tercer curso de Periodismo han demostrado carencias formativas para utilizar imágenes previamente editadas y para utilizar listas de distribución.

Un campo emergente se le abre a la educación: la formación para el uso competente y seguro de las herramientas informáticas. Educadores, profesores, pedagogos, padres y toda persona preocupada por la estabilidad social deberán centrarse en una adecuada autoformación y en una correcta educación a los consumidores de TIC para que se usen las herramientas informáticas desde la competencia, el conocimiento, el respeto y la no agresión.

\section{REFERENCIAS BIBIBLIOGRÁFICAS}

Aliaga, F.; Orellana, A. y Sú́rez, J. (2004) Implantación y utilización de las tecnologías de la información y comunicación en las escuelas. Bordón, 56 (3 y 4), 443-469.

Bernal, A. (2009) Cibermundo y educación. Bosquejo de un nuevo marco formativo en contextos postmodernos. Teoría de la Educación, 21 (1), 71-102.

Bloom, B. S. (1968) Leaning for mastery. Instruction and Curriculum, 1 (2), 1-12.

García, M. y Melaré, D. (2009) Comunidades virtuales prácticas de alfabetización múltiple. Teoría de la Educación: Educación y Cultura en la Sociedad de la Información, 10, (2), 78-101.

García del Dujo, A. (2009) Análisis del espacio en los entornos virtuales de formación. Teoría de la Educación. Revista Interuniversitaria, 21 (1), 103-128.

Irigoin, M. y VArgas, F. (2002) Certificación de competencias. Del concepto a los sistemas. Boletín Técnico Interamericano de Formación Profesional, 12, 46-58.

Leví, G. (2011) Análisis de la formulación de competencias de los grados en las universidades españolas. Tesis doctoral inédita. Madrid, UNED.

LizAno, F. y Trejos, F. (1975) Cinterfor/OIT. Proyecto 128. Programa Regional para el Fortalecimiento de la formación profesional y técnica de mujeres de bajos ingresos. San José de Costa Rica, Banco Mundial.

Palfrey, J. y Gasser, U. (2008) Born Digital: Understanding the First Generation of Digital Natives. New York, Basic Books. 
PRensky, M. (2001) Digital Natives Digital Immigrant. On the Horizon, 9 (5), 1-9.

Poblete, M. (2004) Las competencias: un enfoque paradigmático de la gestión de los RR.UU., en II Symposium de Psicología Organizacional. Monterrey, México.

Rodríguez, N. (2006) Selección efectiva de personal basada en competencias. http:// www.ilo.org/public/spanish/region/ampro/cinterfor/temas/complab/doc/otros/sel_ efe/\#1.\%20En\#1.\%20. En Secretaría de Políticas Públicas de Empleo del Ministerio de Trabajo y Empleo (MTE), Brasil.

Sevillano, M. L (dir.) (2009) Competencias para el uso de herramientas virtuales en la vida, trabajo y formación permanentes. Madrid, Pearson. 